\begin{tabular}{lllllll}
\hline REVISTA IBEROAMERICANA. & Vol. LXII, Núm. 174, Enero-Marzo 1996; 199-208
\end{tabular}

\title{
LA GRAVEDAD Y LA GRACIA: \\ EL DISCURSO DEL SUBCOMANDANTE MARCOS
}

\author{
POR \\ JuAn Pellicer \\ Universitetetioslo
}

\begin{abstract}
Yo que en este mundo no he servido después de ochenta años para nada ... acaso sirva ahora todavía, como David, para lanzar con la honda una de estas piedras, pequeñas y ligeras, de mi zurrón - la más dura, la más pedernal ... Tú, piedra aventurera, y dar justo, justo con ella en la frente misma de Goliat. ${ }^{1}$

León Felipe.
\end{abstract}

Aclamado recientemente por Régis Debray desde la más que sobria tribuna del diario francés Le Monde como "el mejor escritor latinoamericano de nuestros días, el más modernista, el más libre, el de mayor repercusión", ${ }^{2}$ el subcomandante Marcos aparece a partir del primero de enero de 1994, no sólo como representante del Ejército Zapatista de Liberación Nacional (EZLN) sino también como figura prominente de las letras mexicanas.

Líder insurgente y hombre de letras - recuerda algo al Libertador y al Ché, y algo más a Martí-, Marcos revela con las armas y la literatura la existencia de un mundo despreciado, olvidado y enterrado vivo: el mundo de los indios que hay en México. Un mundo subterráneo que desmiente la falsa creencia del mestizaje nacional y que confirma la presencia de dos civilizaciones que no se han fusionado para dar lugar a un proyecto nuevo y su coexistencia ha estado regida invariablemente por la injusta subordinación de la civilización de los indígenas y por el firme propósito de eliminarla y guardarla en un museo. ${ }^{3}$

En cambio, el sistema político y económico mexicano del siglo XX inspirado por la gran revolución nacionalista de 1910 que puso fin al proyecto liberal del siglo XIX, termina hoy irónicamente siguiendo paso a paso al mismo modelo decimonónico que supuestamente había destruido. Concluye agonizando entre la corrupción y la impunidad, pugnas y purgas internas, gangsteriles asesinatos de prominentes dirigentes, asociaciones con el narcotráfico, subordinación humillante al gobierno norteamericano, etc. Cuando el proyecto neoliberal del gobierno mexicano, con el que la economía de mercado se vuelve a poner de moda -

\footnotetext{
1 'Oh, este viejo y roto violín! (México: Fondo de Cultura Económica, 1965) 211.

2 Régis Debray, “A demain, Zapata”, Le Monde (París, 23 de marzo de 1995).

${ }^{3}$ Guillermo Bonfil Batalla, México profundo (1987) (México: Editorial Grijalbo, S.A., 1990) 101.
} 
enésima imitación de sistemas ajenos-, celebraba autocomplacido su supuesto triunfo y su reconocimiento internacional con la entrada en vigor, el primero de enero de 1994, del flamante Tratado de Libre Comercio entre los países de América del Norte, los indios del sur de México se levantaron en armas y la fiesta del gobierno comenzó a convertirse en el gran derrumbe.

A partir de entonces, se inicia la guerra contra el "mal gobierno". Perseguido y cercado en la selva Lacandona por las tropas gubernamentales, el EZLN formula la denuncia de la explotación que históricamente han sufrido los indios y los campesinos de Chiapas, la condena a los gobiernos y hacendados responsables, la exigencia del respeto a los derechos humanos de los indios y los campesinos, y el reconocimiento de su cultura y sus tradiciones como fuente de sus derechos y de su organización administrativa autónoma. Denuncia, exigencia y reconocimiento de hechos y derechos circunscritos a una región del territorio mexicano pero vinculados inseparablemente con la crítica situación política y económica nacional. Denuncia a la corrupción de un sistema supuestamente democrático basado en la omnipotencia del Presidente y su Partido, en la injusticia del corporativismo y la economía de mercado, y en la libertad condicionada al poder económico. A nombre de los indios de Chiapas y de todo el país, y de todos los pobres y los marginados de Chiapas y de todo el país, el EZLN se levantó en armas. Un "¡Ya basta!" que ha recorrido todo México y prácticamente todo el mundo acompañado por el lema de "Democracia, Libertad y Justicia". Y lo que caracteriza a este movimiento, tal vez más que cualquiera otro de sus rasgos peculiares: el EZLN no lucha por obtener el poder político sino sólo por democratizarlo de verdad.

Todas las semanas, desde el primero de enero de 1994, como si fuera por "entregas", la prensa publica las cartas del Subcomandante Marcos que acompañan a los comunicados del EZLN. Las cartas y los comunicados expresan básicamente la denuncia, la exigencia y el reconocimiento aludidos arriba. Las cartas van suscritas por Marcos y los comunicados por el Comité Clandestino Revolucionario Indígena-Comandancia General (CCRI-CG). Dichos textos están formados mediante una retórica muy peculiar y han ido tejiendo un discurso que sin dejar de ser político, económico y social, revela un evidente carácter literario. Este discurso literario es plurigenérico en tanto que su significado se expresa por medio del empleo de diversos géneros literarios, unos serios y otros ligeros o cómicos, tales como la poesía, el cuento, el ensayo, la alegoría, la parodia, la epistola, la sátira y la incorporación de otros textos - desde poemas de Cervantes y de Shakespeare hasta poemas de Antonio Machado, León Felipe y Miguel Hernández y canciones de J. M. Serrat y Stephen Stills.

Se trata de una construcción semejante a los grandes retablos que proyectan el discurso religioso, particularmente el barroco de nuestra época colonial. Tradición española que se estableció en América mediante la intervención y participación de los artífices indígenas. ${ }^{4}$ Si en la arquitectura, el retablo unifica una serie de expresiones diversas - pinturas, relieves, esculturas, alegorías, narraciones, imágenes, etc.- que se muestran en una disposición simétrica de nichos, y es estático, el retablo literario de Marcos, en cambio, es dinámico, está

${ }^{4}$ Clara Bargellini, El retablode la Virgen de los Dolores(México: Centro Cultural/Arte Contemporáneo, A.C., 1993) 24. 
en movimiento, se va configurando con el paso de los días, de las noches y de las lunas, y muestra una confluencia de diversas corrientes o vertientes que es a lo que equivalen los géneros. Efectivamente, el retablo de Marcos consiste en un discurso plurigenérico.

Es el escritor con máscara y con seudónimo. Si al principio el pasamontañas obedecía a una medida de seguridad para ocultar una identidad, hoy la máscara ya sólo enciende la imaginación y así revela una identidad: la del autor o creador. Es así el mejor ejemplo, el más diáfano, de lo que la teoría literaria se ha empeñado en llamar el "autor implícito". No importa su existencia personal - "nombre, señas particulares, etc." sino la existencia que exclusivamente revela el texto. Esta es la que el texto de Marcos muestra en todo su esplendor: una identidad literaria insólita, la de un autor que escribe y sueña "con las botas puestas y el alma en un hilo". 5

La expresión de Marcos entraña, como toda expresión, un fenómeno intertextual que se nutre, entre otras cosas, de tradiciones. ${ }^{6}$ Si el retablo como forma de expresión corresponde a una tradición muy nuestra, la formación de Marcos recoge tradiciones tanto de su paso por centros académicos convencionales donde se pone un mayor énfasis en la cultura occidental, como de su larga e íntima convivencia con los pueblos indígenas del sur de México. Es cierto que las modernas disciplinas universitarias exigen cada vez más la especialización, al grado de preparar un especialista "que sabe cada vez más, de cada vez menos", 7 mientras que, al contrario, en las viejas culturas indias hay una actitud total del hombre frente a la naturaleza que no le impediría al mismo individuo cantarle poéticamente a la luna y estudiarla como astrónomo, o pintar el paisaje y trabajar la sierra, o rezar por la salud y ser médico, etc. ${ }^{8}$ En efecto, el desbordante caudal del discurso de Marcos en el que caben diversos géneros y estilos rompe el modelo del convencional, "especializado", solemne y demagógico estilo retórico de nuestros políticos. Con Marcos y su discurso retórico y literario, se recrean viejas tradiciones mexicanas y, además, vuelve la retórica a sus orígenes poéticos que ya Aristóteles? le atribuía. En las manos de Marcos, la retórica, cuya esencia es la persuasión, deja de ser sospechosa y vuelve a ser, como prescribía Alfonso Reyes, el "arte de la prosa discursiva, literaria en la forma y con un destino útil y sobre todo político"10 pues "cabalga a la vez entre lo poético y lo discursivo". ${ }^{11}$ Hay que recordar también que el género epistolar, hoy de carácter literario y columna vertebral del discurso de Marcos, pertenecía al campo de la retórica en la antigüedad griega. ${ }^{12}$

Lo plurigenérico del discurso de Marcos que es tal vez donde mejor se cifra la magistral destreza con la que desempeña su oficio de escritor, coincide con lo expuesto en el ya célebre

\footnotetext{
${ }^{5}$ EZLN: Documentos y comunicados (México: Editorial Era, 1994) 164.

${ }^{6}$ Harold Bloom, A Map of Misreading (Oxford: Oxford University Press 1975) 32.

${ }^{7}$ México profundo, 58.

${ }^{8}$ México profundo, 56.

${ }^{9}$ The Art of Rhetoric (Londres: Penguin Books, 1991) 217.

10 "La antigua retórica", en Obras completas, tomo XIII (México: Fondo de Cultura Económica, 1961) 374 .

11 "La antigua retórica", 368.

12 "La antigua retórica", 404.
} 
planteamiento de Mikhail Bakhtin ${ }^{13}$ que se refiere a lo que él denomina literatura carnavalizada cuyo origen sitúa en la antigüedad clásica, en algún momento del Helenismo cuando una pluralidad de géneros se unieron formando el ámbito de lo serio-cómico diverso al de los géneros serios - la épica, la tragedia, la historia, la retórica clásica, etc. Lo seriocómico vinculó entonces su perspectiva de la realidad con la del folklore carnavalesco, un modo de entender la relatividad del significado del mundo y su posible pluralidad de significados al contrario de lo que Bakhtin ve como la absoluta seriedad de la retórica, de su racionalidad, de su dogmatismo, de la singularidad del significado. La gran vitalidad de esta perspectiva para entender la riqueza de los posibles significados del mundo estimuló la creatividad y el poder de transformar las cosas. Dentro de lo serio-cómico, explica el teórico ruso, pudo el pasado - mitos y leyendas, dioses y héroes - convertirse en un vivo presente de seres contemporáneos, la tradicional leyenda cedió el paso a la invención libre $\mathrm{y}$, finalmente, aparecieron narraciones multitonales en las que se mezclaba lo serio con lo cómico, lo poético con lo prosaico, lo vulgar con lo refinado, el lujo con la pobreza, el pecado con la gracia, se introducían diversos géneros - cartas, manuscritos, diálogos, diarios, parodias de los géneros serios, citas, alusiones, etc. y el autor solía esconderse tras de varias máscaras. En efecto, el discurso de Marcos puede inscribirse dentro de este campo que, para su estudio, contribuyó a deslindar Bakhtin pues trenza lo que hoy pudiéramos denominar la gravedad de los géneros serios con la gracia de los cómicos. Junto a la proclama política, la ficción del cuento. Al lado del poema, la interpretación de las estadísticas demográficas y económicas. Junto al relato mitológico, la parodia alegorizante de arquetipos novelescos. Paralela a la trágica gravedad de la muerte de las inocentes víctimas de una guerra injusta, la gracia galante del eterno enamorado. Frente al proyecto de una renovación constitucional que efectivamente garantice la convivencia democrática, el viril reto a la cobarde autoridad que volvió a tenderle la trampa. Junto al jovial diálogo salpicado de albureras travesuras, la presencia cotidiana de sus muertos. Al lado de la caza de los miembros del EZLN desatada por las tropas del gobierno a través de la selva, la entereza de una irresistible vocación literaria en pleno vuelo. Frente a la infinita generosidad del "para todos todo, nada para nosotros", la ironía del "para ellos nada, todas para nosotros"14 y el irónico narcisismo de una vanidad cautivadora. Junto a la más radical reivindicación de los derechos de la mujer, una delirante imaginación erótica. Al lado de la conmovedora ternura del mundo de los niños y de los ancianos, lo tragicómico de tenerse que beber sus propios vinos cuando el cerco militar estuvo a punto de prenderlos. Frente al razonado proyecto de reformas administrativas y constitucionales, la alegoría y la parodia de los deliciosos episodios del ingenioso caballero andante el escarabajo Durito y su cronista escudero Marcos.

A lo largo del discurso de Marcos hay dos textos específicos que marcan, por así decirlo, el punto de partida hacia la convergencia de una pluralidad de géneros y su plenitud, que pudiéramos llamar paradigmática. Advierto el punto de partida en el texto titulado

${ }^{13}$ Problems of Dostoevsky's poetics (1929, corregido y aumentado en 1963) (Manchester: Manchester University Press, 1984) 106-127.

${ }^{14}$ Subcomandante insurgente Marcos: "El repliegue nos lleva a casi arañar el cielo", en La Jornada (México, 5 de marzo de 1995) 18. 
"Chiapas: el sureste en dos vientos, una tormenta y una profecía", ${ }^{15}$ y el paradigma en el que se publicó bajo el título de "México: entre el sueño, la pesadilla y el despertar". ${ }^{16}$

Más de un año antes del primero de enero de 1994, en agosto de 1992, en la Selva Lacandona, Marcos redactó el primero de los textos aludidos que, según el departamento de Prensa y Propaganda del EZLN, fue escrito "para buscar que fuera despertando la conciencia de varios compañeros que por entonces se iban acercando a nuestra lucha". ${ }^{17}$ Está dividido, como su título lo indica, en dos "vientos" o partes, en cinco capítulos - tres que corresponden al "Viento primero, el de arriba" y dos al "Viento segundo, el de abajo"y en un breve final representado por "La tormenta" y "La profecía". Cada capítulo va encabezado por un enunciado en el que se expone lo que se va a tratar. Así va, por ejemplo, encabezado el Capítulo Primero: "Que narra cómo el supremo gobierno se enterneció de la miseria indigena de Chiapas y tuvo a bien dotar a la entidad de hoteles, cárceles, cuarteles y un aeropuerto militar. Y que narra también cómo la bestia se alimenta de la sangre de este pueblo y otros infelices y desdichados sucesos". ${ }^{18}$ La ironía es evidente por dos razones: en primer lugar porque esta cabeza parodia a las de los capítulos del Quijote - el espíritu de la obra de Cervantes será una presencia constante en el discurso de Marcos; en segundo lugar porque "enternecer" en este contexto significa precisamente lo contrario de lo que dice; además, el enunciado anuncia un tercer género: lo que viene va a narrar algo. Ya en el encabezado se advierte la presencia de tres elementos que sirven para identificar a diversos géneros: ironía, parodia y narración.

E1 principio del texto va a consistir en una narración peculiar en segunda persona del singular, por medio de la cual el narrador convierte al destinatario de la comunicación en el supuesto protagonista del relato en el que convergen la geografía política, la dinámica del mercado de trabajo, las características de la educación y de la industria, de la salud y de la alimentación. E1 manejo puntual de las cifras estadísticas y de su interpretación indica ahora que lo que había comenzado ligero por la gracia de la narración, se torna grave por el peso del ensayo. Pero luego vuelve a aparecer el espíritu de la narración y dirigiéndose al lector-protagonista registra sus nuevos recorridos, ahora por los altos de Chiapas demografía y turismo-; las cifras estadísticas no se equivocan: “... hay unas siete habitaciones por cada mil turistas, mientras que hay 0.3 camas de hospital para cada mil chiapanecos". ${ }^{19}$ La ironía de los parques nacionales administrados por el ejército seguramente un nuevo tipo de "especialización"-, de los flamantes edificios modernos que el candoroso lector-protagonista - víctima de la ironía - cree que son universidades u hospitales pero que resultan ser cuarteles y cárceles y prostíbulos.

En el Capítulo Segundo, encabezado también a la usanza del Quijote, la narración, por medio de la sátira, describe la corrupción y relata los atropellos del virrey —el gobernadory sus señores feudales, es decir, los ganaderos de la región. A1 lado de la caricatura, el golpe de las estadísticas: Chiapas ostenta el más alto índice de mortalidad en México. La culpa

\footnotetext{
15 Documentos, 49.

${ }^{16}$ La Jornada (México, 24 de septiembre de 1994).

${ }^{17}$ Documentos, 49.

${ }^{18}$ Documentos, 50.

${ }^{19}$ Documentos, 55.
} 
la tienen, en primer lugar, enfermedades curables que van desde infecciones respiratorias haste el sarampión.

E1 Capítulo Tercero continúa el relato irónico y satírico pero además el narrador registra un pedazo de la visión indígena de la realidad, lo que cuentan los viejos más viejos de las comunidades: que Zapata no ha muerto y volverá, que así como el viento, la lluvia y el sol le dicen al campesino cuándo hay que barbechar, sembrar y cosechar, también le dicen que la esperanza se siembra y se cosecha, que ahora es la hora de cosechar rebeldía. La lucha que encabezó Zapata hace ochenta años sigue estando muy lejos de concluir y su arraigo entre los indígenas obedece no sólo a su orientación agraria sino a su total identificación con formas reales de vida forjadas a través de los siglos. ${ }^{20}$ Por éso Zapata es imperecedero. El capítulo concluye en voz baja, con fina sordina, como suelen hablar los indios: "'Zapata' repiten quedo los pobres jóvenes; 'Zapata' insiste el viento, el de abajo, el nuestro". ${ }^{21}$ La alusión al viento como el impulso de un antiguo e invencible aliento da pie al siguiente capítulo.

Ubicado ya bajo el rubro de "Viento segundo, el de abajo", el Capítulo Cuarto, encabezado por el mismo estilo paródico de los demás, se ocupa de elaborar una interpretación histórica del significado de la dignidad y la rebeldía indígenas y señala ciertas características de las más viejas tradiciones indígenas de la región que han funcionado como la única posibilidad de supervivencia de esos pueblos, con las que se identificó el zapatismo: el trabajo colectivo, el pensamiento democrático y la sujeción al acuerdo de la mayoría. Alegóricamente, en el viento de abajo encarna la dignidad y la rebeldía de los indígenas, y en su original aliento, el arraigo de sus tradiciones irrenunciables.

Finalmente, el Capítulo Quinto consiste en una dramática narración en presente de seis muy significativos eventos en los cuales las autoridades rechazan las legítimas demandas de los campesinos indígenas de diversos poblados. Una marcha indígena que se desplaza 1,106 kilómetros rumbo a la ciudad de México y 1,106 de regreso sin haber obtenido nada. Relatos de marchas y de ocupaciones, de arrestos y de torturas con el mismo desenlace de siempre: todo queda igual, todo sigue igual. Finalmente, el narrador, todavía en el uso del presente, relata el sueño del joven Antonio, personaje que reaparecerá con frecuencia en los siguientes textos de Marcos. Al lado de la desoladora realidad, el sueño con un mundo feliz que no consiste en nada extraordinario sino en lo que no es más que un mínimo básico pues sueña Antonio que la tierra que trabaja le pertenece, que le pagan por su trabajo con justicia, que hay escuela y medicina y electricidad y comida, que es su gente la que gobierna y que lo hace razonablemente, que debe luchar para tener ese sueño. Simétricamente, los sueños del virrey y de los señores feudales son pesadillas: sueñan, sin dormir, que les quitan lo que se han robado. ${ }^{22}$

Al final, queda redondeada la alegoría de los dos vientos, el de arriba y el de abajo, y claramente identificadas las referencias o significados de las dos figuras a las que corresponden los dos vientos. Lo que sigue, "La tormenta" y "La profecía", narraciones en

\footnotetext{
${ }^{20}$ México profundo, 105.

${ }^{21}$ Documentos, 62.

${ }^{22}$ Documentos, 66.
} 
futuro, constituye el remate natural ya en el puro plano de la alegoría. Una "tormenta" que nacerá del choque de los dos vientos y "un mundo que ya no será el mundo, sino algo mejor". ${ }^{23}$

Así, mediante la combinación de la parodia, la ironía, la sátira, la narración en pasado, en presente y en futuro, en segunda y en tercera personas, la alegoría, la historia, los sueños, la interpretación de las estadísticas económicas y demográficas, el comentario político, queda marcado el punto de partida de esta convergencia de la gravedad de ciertos géneros y la gracia de otros a partir del cual se va a ir levantando y poblando el retablo que forma el discurso de Marcos.

Frente al segundo de los textos que mencioné arriba, "México: entre el sueño, la pesadilla y el despertar", estamos no sólo frente a un nicho central del gran retablo que es como puede verse la obra de Marcos, sino también frente a una estructura que reproduce, a escala, al propio retablo. Además de los géneros incluidos en el texto comentado arriba, en éste está integrada la poesía y, además, lo que dentro del género epistolar, se ha convertido en la divisa del discurso de Marcos: la posdata. La del subcomandante ha dejado de funcionar como mero apéndice de la carta y ha pasado a convertirse, primero, en una sección con la misma importancia de las otras secciones que incluye un determinado texto y, más tarde, en la parte más extensa e importante de la comunicación reduciéndose el contenido de la carta propiamente dicho a una mera introducción. La posdata, a su vez, suele incluir narraciones, parodias, sátiras, poemas propios y ajenos, diálogos, sueños, leyendas, etc. Este recurso, que en la pluma de Marcos bien podría ya tipificarse como un sub-género, le ha brindado a su autor la posibilidad de subrayar la espontaneidad de su expresión, la que, a su vez, permite acentuar aún más la sinceridad de su mensaje; también contribuye a mantener el atractivo aire informal, en cierta forma íntimo, diríase fraternal, que define el carácter de la retórica de Marcos. Además, este tipo de posdata habrá de tener el encanto de personificarse como por ejemplo esta que encabeza con la proverbial gracia del autor cuestiones de la más grave índole como la cobarde trampa tendida por el Secretario de Gobernación a Marcos a principios de febrero de 1995: "A CONTINUACION NUESTRA GUSTADA SECC1ON 'LA POSDATA RECURRENTE ENLA TRANSGRESION Y LA ILEGALIDAD'. P.D. QUE RIE Y HACE CARACOLITOS AL DESTINATARIO". ${ }^{4}$

"México: entre el sueño, la pesadilla y el despertar" está formado por tres capítulos, cada uno encabezado por la parodia otra vez a los encabezados de los capítulos del Quijote. El primero "que narra de los cantos neoliberales de 24 sirenas ..."25 va introducido por un poema en el que habla la Patria de sus dolores seguido de una descripción de las principales características de los Méxicos tan diversos como son el de la planta alta, el de enmedio, el de abajo y el del sótano. Las descripciones llevan intercaladas narraciones, instrucciones para lograr que un "ciudadano" del México de arriba sea nombrado, algún día, "El hombre del año" por alguna institución extranjera. Asimismo incluye un nicho o "espacio para paradojas de promoción turística” en el que, arriba, se expone la lista de los 24 más ricos de

${ }^{23}$ Documentos, 66.

${ }^{24}$ Subcomandante insurgente Marcos: "La muerte nos visita vestida de verde olivo; cada segundo, un volado", en La Jornada (México, 25 de febrero de 1995) 16.

25 "México: entre el sueño ...", 2. 
México, el más rico de los cuales tiene una fortuna que asciende a 6,600 millones de dólares y el más pobre a sólo mil millones de dólares, mientras que abajo se presenta la lista de los 24 municipios más pobres de México en los que hay un promedio del $67 \%$ de población analfabeta en los mayores de 15 años, el $90 \%$ no tienen la primaria completa, el $87 \%$ de la población no tiene drenaje ni excusado ni electricidad, etc., etc. Este capítulo también dedica un nicho a las mujeres que muy feminísticamente se denomina: "Las mujeres: doble sueño, doble pesadilla, doble despertar".

E1 Capítulo 2 anuncia que narrará tormentas, ventarrones y marejadas y "otras increíbles (porque no las cree nadie) historias electorales que cuentan en la flota enemiga". ${ }^{26}$ Introducido por otro poema en el que habla la Patria ahora de sus temores, consiste primeramente en un agudo analísis político de los resultados de las elecciones presidenciales que tuvieron lugar en México el 21 de agosto de 1994. Son las tres lecturas de los resultados electorales que expone Marcos las que proporcionan una interpretación del aparente triunfo del partido del gobierno a la vez que comprueban el efectivo rechazo mayoritario a ese partido que es lo que realmente significó la votación en favor de los partidos de la oposición sumada a la abstención.

Por último, el Capítulo 3, bajo el subtítulo de "México: entre el dolor y la esperanza", esta formado por dos poemas de Marcos, uno en el que vuelve a hablar la Patria, ahora con optimista esperanza, y otro supuestamente escrito por el Subpirata que sigue a un comentario político-alegórico del contexto de la Convención de Aguascalientes y de las elecciones presidenciales, y por tres posdatas que incluyen fragmentos de poemas de Miguel Hernández y León Felipe, y un relato que recuerda al Popol Vuh.

E1 comentario político se transforma en relato alegórico, el del navío -los neozapatistas y la sociedad civil - en el mar del desánimo, de la desesperanza, de los conflictos; a pesar de todo, los remeros amordazados del sótano siguen remando. Obviamente que el mar, el viento, la nave, el timón, la travesía, los remeros amordazados, el subpirata, etc., son elementos alegóricos, significantes trasparentes de la lucha del EZLN.

Para concluir, aparecen las posdatas personificadas. La primera "que, de la mano de Toñita, viene a pedir un cuento", ${ }^{27}$ relata la visita que le hace la niña Toñita al autor mientras éste escribe; lleva en sus bracitos un olote que es su muñeco y le pide a Marcos que le cuente un cuento. Este cuento referirá una conversación que había tenido el propio Marcos con el viejo Antonio en la cual éste, a su vez, cuenta, entre otras cosas, la historia de la creación del sol y de la luna que evoca al Popol Vuh. Relata el viejo Antonio cómo los dioses soñaron con la aparición del fuego entre el agua, cómo:

una herida apareció, una rajadita sobre el agua-noche, una palabrita así chiquita que se bailaba y grande se hacía y chiquita ... y rápido se dieron los dioses en hacerle casita a la palabrita ésa que en medio bailaba, que en silencio bailaba... los dioses sacaron acuerdo ... de llevar para arriba el fuego, para el cielo, para que el agua noche no lo alcanzara ... y echaron en discutir quién debía llevar el fuego para arriba y morirse abajo para vivir arriba ... y dijeron que vaya el dios más blanco, porque era el más hermoso y así el fuego sería hermoso allá arriba, pero el dios blanco fue cobarde ... entonces el más negro y más feo

\footnotetext{
26 "México: entre el sueño ...", 5.
}

27 "México: entre el sueño ...", 8. 
de los dioses, el ik', dijo que él lo llevaba para arriba al fuego ... y se quemó ... y negro se puso y gris después y blanco y amarillo y naranja después y rojo luego y fuego se hizo, y se levantó palabriando hasta el cielo y ahí se quedó redondo y en veces es amarillo y en veces naranja, rojo, gris, blanco y negro, y 'sol' le pusieron ... y el agua-noche se echó para un lado y se vino la montaña. ${ }^{28}$

E1 dios blanco se apenó y tanto lloró que se tropezó, cayó en el fuego y también se fue al cielo pero siguió llorando por su cobardía y como bola blanca quedó al lado del sol y le pusieron "luna" y fue tras del sol para pedirle perdón y así hubo día y hubo noche. A los otros dioses también les dio pena y vergüenza y también ellos se arrojaron al fuego.

Una vez concluido el relato mitológico, el viejo Antonio —en el relato para Toñitale recuerda a Marcos el significado de lo negro al separar con sus manos un tizón encendido de la hoguera que, antes de hacerse negro, va del naranja al amarillo al blanco al gris y finalmente al negro y, por éso, agrega Antonio, un rostro cubierto de negro guarda la luz y el calor que le hacen falta al mundo. Otras cosas pasan en el cuento que escucha Toñita y que, obviamente, se refieren a la decisión de cubrirse los rostros con pasamontañas negros, pero lo que me parece más notable no está sólo en las coincidencias del estilo, de ciertos eventos y del significado que pueden advertirse en la versión de Antonio y en la de la creación del mundo del Popol Vuh, sino en la coincidencia que hay entre el principio del mundo en la vieja leyenda mitológica y el principio de un mundo nuevo como parece que se está gestando en las montañas del sureste mexicano. E1 valor de la leyenda está en la efectiva posibilidad de que los eventos narrados en ella se conviertan en una alegoría que exprese un presente tan real y objetivo como pueden serlo, por ejemplo, la vida y la muerte cotidianas. Recuérdese que la legendaria águila de los viejos aztecas devorando a la serpiente sobre un nopal se convirtió en alegoría del presente de los nuevos aztecas cuando éstos efectiva, real y objetivamente se comieron a las serpientes que infestaban aquel islote cubierto por nopaleras y construyeron ahí su prodigiosa ciudad. La alegoría del águila y la serpiente pudo expresar entonces una realidad histórica. Por su parte, lo más significativo de la leyenda del viejo Antonio, es que el origen del fuego fundido con la palabra representa alegóricamente el origen de este levantamiento indígena de hoy en el que la palabra desempeña un papel central y definitivo; y cada elemento del relato mitológico corresponde a elementos de la realidad presente ya que los indios - representados alegóricamente por los dioses- efectiva, real y objetivamente mueren en el fuego, y mueren para poder vivir, para que otros puedan vivir. Alegóricamente son el sol que da luz y calor. Este puede ser el sentido del "morir para vivir" del viejo Antonio (parecido, por cierto, al de los místicos españoles).

Para rematar esta larga posdata en la que predomina la gravedad del viejo Antonio y del secular espíritu de la leyenda, reaparece con la mayor fortuna literaria, la incomparable gracia, la que Marcos sabe y puede expresar tal vez mejor que nadie: "Toñita se levanta para irse. 'Falta el beso', le digo. Se acerca y rápido me pone el olote en la mejilla, se corre. ‘Y eso?' protesto. Contesta riendo: Es tu beso pues ... el cuento era para el muñeco, así que ya te dio tu beso'. Se va corriendo ...". ${ }^{29}$

28 "México: entre el sueño ...", 8.

29 "México: entre el sueño ...", 8. 
La segunda de las posdatas, que lleva como epígrafe (¿quién ha visto una posdata con epígrafe?) una estrofa del poema "E1 vuelo de los hombres", de Miguel Hernández, reitera el significado de la alegoría que revela la posdata anterior ya que consiste en un relato de la historia de "Hugo, nombre de guerra de este príncipe tzeltal, en porte y nobleza", ${ }^{30}$ uno de los fundadores del EZLN, que se hacía llamar "señor Ik" (que quiere decir "señor negro"), y que desapareció en los combates —el fuego-del 2 de enero de 1994. Es más que evidente que la vida y la muerte del señor Ik' corresponden precisamente a la alegoría que puede leerse en el relato del viejo Antonio. La gravedad de esta posdata contrasta con la gracia de su vecina, la última, "que se despide con un "no me olvides", y en la que se "escucha" a León Felipe decir su conocida "Canción marinera", evocadora de la alegoría del navío, el mar y el tesoro verdadero, tan cara también a Marcos.

Esta íntima vecindad de los géneros que pueblan el discurso de Marcos, en la que se percibe el significativo contraste de la gravedad y la gracia, sugiere la existencia de más de una voz en el texto. La yuxtaposición de parodias, relatos uno dentro del otro, diálogos, poemas, alegorías, leyendas, etc., revelan una cierta pluralidad de voces por medio de las cuales habla el texto. Su yuxtaposición marca una tensión que Bakhtin llamó "dialógica"31 y que permite al autor proyectar un determinado significado mediante la presencia simultánea de dos voces inseparables que en el caso del discurso de Marcos están representadas por la voz de la gravedad y por la de la gracia. Su elocuente contrapunto corresponde a la piedra sobre la que se levanta el retablo del discurso; en dicho contrapunto se cifra, acaso, la fortuna de la retórica de este joven maestro de las letras y de las armas. Es la piedra del cimiento y también la de la honda.

\footnotetext{
30 "México: entre el sueño ...", 8.

31 "Discourse in the Novel", en The Dialogic Imagination (1975) (Austin: University of Texas Press, 1981) 314 .
} 